\title{
FORMAS DE LA TRANSMISIÓN DEL SABER ISLÁMICO A TRAVÉS DE LA TAKMILA DE IBN AL-ABBĀR DE VALENCIA (época almohade)
}

\author{
Por \\ JESÚS ZANÓN
}

\section{Planteamiento y objetivos}

Las formas o modos concretos de transmisión del saber en el mundo islámico fueron muy pronto codificados, coincidiendo con la fijacion de los textos fundamentales de la tradición profética (hadit) y del derecho (fiqh). No obstante, existen discrepancias entre diversos autores y tratadistas, que podrían ser debidas a varias razones: usos y tradiciones locales, innovaciones de determinados transmisores, carácter particular de las materias transmitidas, etc. G. Vajda mostró la necesidad de contrastar las exposiciones teóricas con documentación en la que se refleja lo que realmente ocurría en la práctica. En concreto, llevó a cabo una serie de estudios a partir de repertorios de transmisores de obras (barnāmầ o fihrist) y de certificados de audición extraídos de determinadas obras manuscritas ${ }^{2}$. Pero, además de este

(1) Los estudios sobre Ibn al-Abbār han sido recientemente impulsados gracias al congreso "Ibn alAbbar i el seu temps" desarrollado en Onda los días 20-22 de febrero de 1989 y organizado científicamente por la División departamental de Estudios Árabes e Islámicos de la Universidad de Alicante. Las actas fueron publicadas con el título $I b n$ al-Abbar, polític i escriptor àrab valencià, Valencia, 1990.

(2) Estos trabajos fueron reunidos tras su fallecimiento en un volumen titulado La transmission du savoir en Islam (VIIe-XVIIIe siècles), Londres, 1983. Debe añadirse: G. Vajda, Les certificats de lecture et de transmission dans les manuscrits arabes de la Bibliothèque Nationale de Paris, París, 1956. 
tipo de fuentes, los diccionarios biográficos pueden arrojar mucha luz sobre el tema. La gran cantidad de referencias que allí puede encontrarse permite realizar al mismo tiempo un análisis particularizado y un análisis de las frecuencias.

El presente trabajo consistirá en el análisis de los términos y expresiones relativos a la transmisión del saber que aparecen en las biografías de la Takmila de Ibn al-Abbār (m. 658/1260) fallecidos después del año 540 de la hégira $(=1145)$. El total de biografías asciende a $1.642^{3}$. El estudio se circunscribe a un espacio geografico-temporal homogeneo: al-Andalus en las épocas almorávide y almoha$\mathrm{de}^{4}$, de modo que sirva de punto de partida y de contraste para investigaciones similares que se realicen en el futuro en ámbitos geográficos y temporales distintos ${ }^{5}$.

Se tomarán en consideración únicamente los términos que vinculan a los personajes biografiados con sus maestros, y se dejarán de lado los que ponen en relación a los biografiados con sus discípulos, ya que la mención a éstos últimos en las biografías tiene un carácter secundario y no exhaustivo ${ }^{6}$.

He aquí algunas consideraciones sobre la cuantificación realizada. Es habitual en la Takmila, y en otras obras del género biográfico, que el autor reduzca a una unidad términos que debieran repetirse, agrupando a los maestros según el modo de transmisión. Así, por ejemplo: sami a (el personaje biografiado) min [fulān] wa[fulān] wa-[fulān] wa-[fulān]... La expresión samica min ("escuchó de"), se contabilizará tantas veces como maestros se citen, pues se aplica a cada uno de ellos. Por otro lado, en algunas ocasiones (pocas) aparecen dos obras distintas transmitidas según un mismo modo de transmisión. Por ejemplo qara'a al-Muwatta'

(3) Aprovecho para este estudio la base de datos confeccionada para imi Tesis Doctoral, La vida intelectual en al-Andalus durante la época almohade: Estudio de la Takmila de Ibn al-Abbär, dirigida por la Dra. Manuela Marín, y defendida en la Universidad Complutense en el año 1991.

(4) Teniendo en cuenta que los primeros personajes analizados fallecen en 540/1145, quiere decir que su período de formación se sitúa a lo largo del último tercio del siglo anterior, coincidiendo con el asentamiento de los almorávides en al-Andalus.

(5) La Takmila li-Kitäb al-sila de Ibn al-Abbär ha sido objeto de varias ediciones, todas incompletas. Se manejarán las siguientes: edición de ${ }^{\mathrm{c}} \mathrm{I}$. al-c Attārs al-Husaynī de El Cairo, 1955 (citada IA(Cairo)); esta edición quedó inconclusa y es necesario utilizar el vol. II de la edición de $F$. Codera, publicada en Madrid, 1887 (citada IA(Codera)). A partir de la biografía $n^{2} 1797$, F. Codera utilizó un manuscrito resumen de la Takmila; es preciso entonces acudir al "Apéndice a la edición Codera de la "Tecmila" de Aben al-Abbar" editado por M. Alarcón en Miscelánea de Estudios y textos árabes, Madrid, 1915, pp. 147-690 (se cita IA(Codera+Alarcón). Esta última edición contiene además un conjunto de biografías no recogidas por Codera ni por la edición de El Cairo (citado IA(Alarcón)).

(6) De modo general se puede decir que la referencia a discípulos responde a un interés de Ibn alAbbār por señalar a sus propios maestros o a sus fuentes, o bien se trata de hijos de los biografiados, o de personajes muy destacados. 
wa-Șahih al-Bujāri "leyó el Muwatta' y el Sahịh de al-Bujārī". También en este caso qara'a se contará una vez por cada obra. Se evitarán los nombres propios (en ocasiones suplidos por fulān, fulano), con el objeto de no recargar demasiado el trabajo con información que no es esencial. Por la misma razón se evitará dar referencias cronológicas y bibliográficas de personajes y obras muy conocidos.

Previo al análisis de los términos de la Takmila, se trazará una síntesis de los modos de transmisión según los teóricos. Se seguirá fundamentalmente un texto de usūl al-hadīt o fundamentos de la tradición profética, el Taqrïb wa-l-taysir li-ma rifa sunan al-baš̄ir al-nadīr de al-Nawāwī (m. 676/1180) ${ }^{7}$, cuyas consideraciones pueden generalizarse al resto de las ciencias islámicas. Además, alNawāwī señala las opiniones de sus antecesores, y la magnífica traducción anotada de W. Marçais, con referencias a las fuentes fundamentales de hadit $\mathrm{y}$ del resto de las ciencias islámicas, nos dispensa de acudir directamente a dichas fuentes.

Tres serán los objetivos que nos proponemos cumplir: 1) clarificación de la terminología, a veces ambigua, de Ibn al-Abbār; 2) establecimiento de una jerarquía de los modos de transmisión segín la frecuencia de uso, y de una jerarquía según su valor intrínseco; 3) precisiones sobre las modalidades que se dan en la práctica de las formas de transmision.

\section{Los modos de transmisión de las ciencias islámicas según la teoría.}

Según al-Nawāwī, los modos de transmisión del hadīt, por orden descendente de valor, son ocho: sama $\tilde{a}^{\mathrm{c}}$ (audición), qirā'a (recitación), iŷāza (licencia), munāwala (entrega), kitāba (escrito), iclām (declaración), wașiyya (testamento) y wiŷăda (hallazgo).

Los dos primeros implican la presencia física del discípulo junto al maestro.

2.1. Audición $\left(s a m \bar{a}^{\mathrm{c}}\right)^{8}$. El discípulo escucha directamente del maestro, quien puede citar de memoria o leer de un libro. La mayoría de los autores considera la audición el modo de transmisión de mayor valor. Las formulas empleadas por los

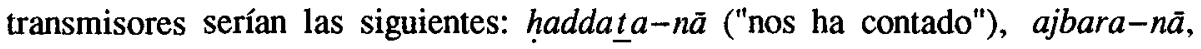
("nos hizo saber") anba'a-nā ("nos ha informado"), samic tu ("he escuchado"), qāla

(7) Traducido y anotado por W. Marçais en distintos números de la revista Journal Asiatique, y reimpreso como monografía con el título de Le Taqríb de En-Nawawi, París, 1902. Para otros tratados de usūl al-hadịt, véase la introducción de W. Marçais a la obra citada.

(8) Taqrib, 103-105. G. Vajda, "De la transmission orale du savoir", p. 2, en La transmission du savoir en Islam, op cit. 
la-nā ("nos ha dicho") y dakara la-nā ("nos ha mencionado"). Existen posiciones divergentes sobre el valor y la aplicación especial de cada una de estas fórmulas.

2.2. Recitacion ( $\left.q i r a a^{\prime} a\right)^{9}$. El discípulo recita ante el maestro, ya sea leyendo o citando de memoria. Ciertos tradicionistas denominan este modo de transmisión 'ard. Según añade W. Marçais, el término qirä'a tiene un sentido amplio al considerarse tanto al discípulo que recita como al que escucha recitar; en cambio, el término ard tiene un sentido estricto: recitación efectuada personalmente. No existe unanimidad en considerar la audición superior a la recitación. Al-Nawāwī cita a autores que los consideran iguales en valor, como el fundador de la escuela jurídica mālikí Mălik b. Anas, o a partidarios de la recitación como modo más elevado. Las fórmulas más indicadas para transmitir tradiciones recibidas por recitación son: qara'tu cala fulān ("he leído ante fulano"), y quri'a 'alà fulān waană $a s m a^{c}$ ("se ley6 ante fulano y yo he escuchado"). Existen partidarios y adversarios de emplear las formulas citadas anteriormente para la transmisión por audicion: haddata-na ("nos ha contado"), ajbara-nä, ("nos hizo saber") y sami ${ }^{\circ} t u$ ("he escuchado").

2.3. Licencia $(i \hat{y} a \tilde{z} a)^{10}$. Es un modo de transmisión de evolución complejo y muy controvertido. Básicamente se trata de una autorización dada por el maestro al discípulo para transmitir. En un origen se daba iŷāza tras la audición o la recitación, pero a partir del siglo III/IX, cuando ya se habían fijado por escrito las más importantes colecciones de tradiciones, la iŷăza se convirtió en un modo de transmisión independiente. Al-Nawāwī indica varias modalidades, de las que recogemos solamente algunas: 1) el maestro especifica a quién da la licencia y la obra que autoriza transmitir; 2) especifica la persona a la que da licencia, pero no la obra; 3) en la iŷāza cämma ("licencia general") no se señala ninguno de los dos términos.

2.4. Entrega (munāwala) ${ }^{11}$. Puede ser de dos tipos: 1) unida a la licencia

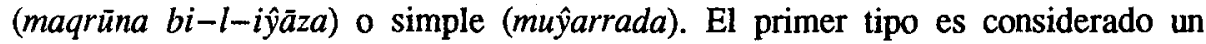
modo especial de iŷāza o licencia de muy alto valor. En cambio, las tradiciones recibidas según el segundo tipo, sin licencia, no pueden ser transmitidas.

(9) Taqrib, 105-115. G. Vajda, "De la transmisión orale", p. 2.

(10) Taqrỉ, 115-126. W. Marçais (p. 115, n.2) señala que la iŷäza se aplica al conjunto de las ciencias islámicas. Para un detallado conocimiento teórico de la iŷãza y sus modalidades es necesario tener en cuenta la bibliografía citada por G. Vajda en Les certificats de lecture, p. V nota 1.

(11) Taqrib, 126-133. G. Vajda, "De la Transmission orale", p. 3. 
El maestro entrega al discípulo un original, o un ejemplar cotejado con el original, donde se consignan las tradiciones oídas por él. Según otra modalidad, el discípulo presenta al maestro un cuaderno con las tradiciones recogidas por éste, que deberá examinarlas antes de autorizar su transmisión. Ésta última modalidad es llamada 'ard al-munāwala ("presentación de la entrega"). Las fórmulas más empleadas para señalar este tipo de transmisión son haddat $a-n \bar{a}(n \bar{l})$ o ajbara$n \bar{a}(n \bar{l})$. Según G. Vajda, raramente se utiliza la expresión nāwala.

2.5. Kitāba (escrito) ${ }^{12}$. El maestro escribe (o hace escribir) para un discípulo las tradiciones por él recogidas. Es indiferente que el discípulo se encuentre o no presente. Existen dos modalidades según se acompañe o no de licencia (iŷāza). En el primer caso, se le confiere el mismo valor que a la transmisión por entrega (munāwala) también acompañada de licencia. La fórmula empleada sería una de las siguientes: mā katabtu la-ka, mā katabtu ilay-ka, mä katabtu bi-hi ilay-ka. Para la transmisión por escrito no acompañada de licencia, existe discrepancia de criterios en cuanto a su valor, siendo incluso negado por algunos teóricos.

Los siguientes modos de transmision eran de validez muy controvertida.

2.6. Il lām (declaración) ${ }^{13}$. El maestro declara a un discípulo que cierta tradición o cierta obra ha sido por él escuchada, sin autorizar al discípulo a transmitirla a su vez. Al-Nawāwĩ cita autores partidarios y adversarios de esta forma de transmisión. Él se declara de acuerdo con los segundos.

2.7. Wasiyya (testamento) ${ }^{14}$. El maestro, antes de morir o de salir de viaje, lega a un discípulo un cuaderno con las tradiciones por él recogidas. La mayor parte de los teóricos restan validez a este tipo de transmisión.

(12) Taqrỉ, 133-136. Según anota W. Marçais (p. 133, n. 2), este modo de transmisión existe también para las ciencias coránicas y las filológicas, pero se les aplica el término de mukātaba en lugar de kitäba. G. Vajda, "De la transmission orale", p. 3.

(13) Taqrib, 136-137. Vajda, G., "De la transmission orale", p. 3.

(14) Taqrïb, 137. Vajda, G., "De la transmission orale", p. 3. 
2.8. Wiŷãda (hallazgo) ${ }^{15}$. Alguien encuentra un escrito con tradiciones de puño y letra de su transmisor. La mayor parte de los autores restan validez a la transmisión de tradiciones conocidas de este modo ${ }^{16}$.

3. Análisis de expresiones y términos de la Takmila de Ibn al-Abbār que hacen referencia a la transmisión de las ciencias islámicas

\subsection{Expresión samic $a$ [materia/obra] min fulān.}

Cabe aceptar que la expresión sami a min ("escuchó de"), debe identificarse con la transmisión por audición $\left(s a m \bar{a}^{c}\right)$. Es la expresión más utilizada en la Takmila, citada en 2387 ocasiones. No obstante, en la mayor parte de los casos $(84 \%)$, no se expresa la materia u obra objeto de tal audición, según el recuento siguiente:

\begin{tabular}{|l|r|r|}
\hline samica min [fulān] [obra] & 262 & $11 \%$ \\
\hline samica min [fulān] [materia] & 117 & $4,9 \%$ \\
\hline sami ca min [fulān] (sin especificar obra ni materia) & 2008 & $84,1 \%$ \\
\hline & & \\
\hline total & 2387 & $100 \%$ \\
\hline
\end{tabular}

Hay que señalar, en primer lugar, que la única materia citada tras la expresión sami a min es la tradición profética o hadit. Sorprende que otras disciplinas, tanto o más frecuentes que el hadit

(15) Taqrib, 137-140. Según W. Marçais, op. cit., 137, nota 3, el qāđ̄̄ c Iyād denomina a este modo de transmisión al-jatt. En la Takmila, siempre que aparece este término, tiene el sentido de escrito autógrafo, como pör ejemplo: rawà al-Muwatta' can [fulän] fi sana 504 wa-kataba-hu bi-jatti-hi ("transmitió el Muwatta' de [fulano] en el año 504, y lo escribió de su puño y letra") (IA(Cairo) $n^{2} 1297$ ). Señala también W. Marçais que la wiŷāda es común a las ciencias coránicas y a las filológicas. G. Vajda, "De la transmission orale", p. 3.

(16) al-Silafĩ (478/1085 - 576/1180), maestro de un gran número de andalusíes, en su al-Waŷiz $f i$ dikr al-muŷāz wa-l-muŷtz, reduce los modos de transmisión, también por orden descendente de valor, a tres: samä', munāwala e î̀āza. Señala también la terminología que adopta: 1) anba'a-ni ("me ha informado"), cuanto el maestro y el discípulo se encuentran en presencia el uno del otro; 2) kataba ilayya ("me ha escrito"), cuando la transmisión se efectúa por correspondencia; 3) ajbara-nā ("nos hizo saber") haddața-nā/haddața nī ("nos ha contado/me ha contado") y $\operatorname{sami}^{c} t u$ ("he escuchado"), cuando se trata de una audición que no implica î̀ăza. Véase G. Vajda "Un opuscule inédit d'as-Silafi", Bulletin d'information de l'Institut de Recherche et d'Histoire de textes, 14, París, 1966, pp. 85-92; reimpreso en G. Vajda, La transmission du savoir en Islam, XIII. 
('arabiyya), no aparezcan nunca señaladas tras la expresión sami ${ }^{c} a$, y sí, en cambio, tras la fórmula ajada ${ }^{c} a n$, según veremos más adelante. ¿Nos encontramos ante una especialización de fórmulas aplicadas a materias (no a obras), de modo que

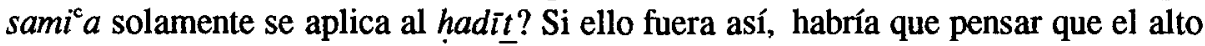
porcentaje de expresiones samic a min [fulän] sin especificación de materia podría equivaler en muchos casos a samic a al-hadīt min [fulān].

Consideremos ahora las referencias a obras concretas. Éstas, como se puede observar en el siguiente cuadro, son de distinta índole, pero destacan también por su frecuencia las obras de hadit sobre las de otras disciplinas:

\begin{tabular}{||l|r|r|}
\hline Obras de hadīi & 133 & $50,8 \%$ \\
\hline al-Muwatta $^{17}$ y obras de derecho & 45 & $17,2 \%$ \\
\hline Obras sobre lecturas coránicas & 10 & $3,8 \%$ \\
\hline Obras de filología, adab y poesía & 29 & $11,1 \%$ \\
\hline Otras obras & 45 & $17,2 \%$ \\
\hline & & \\
\hline Total & 262 & $100 \%$ \\
\hline
\end{tabular}

Llama la atención el alto porcentaje de obras de hadīt si se compara este cuadro con el gráfico 1 , donde se reflejan porcentualmente las disciplinas cultivadas por los mismos personajes biografiados por Ibn al-Abbār que sirven de base para el presente estudio. Se observa que el hadit no es precisamente la materia de mayor preferencia, estando por delante las ciencias coránicas, el adab, el fiqh y la filología ${ }^{18}$.

(17) El Muwatta' en al-Andalus podía ser tan necesario para los estudios de derecho como para los de tradicionès proféticas. I. Goldziher da testimonios de cómo en al-Andalus nunca fueron estimados los Sunan de Ibn Māŷa, colección de tradiciones considerada canónica en Oriente, y en su lugar se utilizaba el Muwatta' de Mālik (véase Muslim Studies, II, Londres, 1971, pp. 240-2). El interés por el estudio de las tradiciones incluidas en la obra de Mālik nació como resultado de la controversia entre mālikíes y partidarios de la tradición del profeta (véase Fierro, M I., "The Introduction of hadith in al-Andalus", Der Islam, 66, 1 (1989), pp. 80-90).

(18) Es necesario remarcar que la comparación sólo es válida hasta cierto punto, puesto que los datos del cuadro reflejan obras transmitidas a discípulos, mientras que los del gráfico representan las disciplinas por las que se distinguieron los mismos discípulos tras llegar a un estadio de madurez. El gráfico ha sido tomado de mi Tesis Doctoral inédita citada anteriormente. Para su lectura hay que aclarar que cada disciplina está representada por dos columnas. La primera representa a los personajes fallecidos entre los años 540/1145 y 595/1198 de la hégira, la mayor parte de los cuales se instruirían ers época almorávide, y la segunda para los personajes fallecidos después del 596/1199. formados en época almohade. 


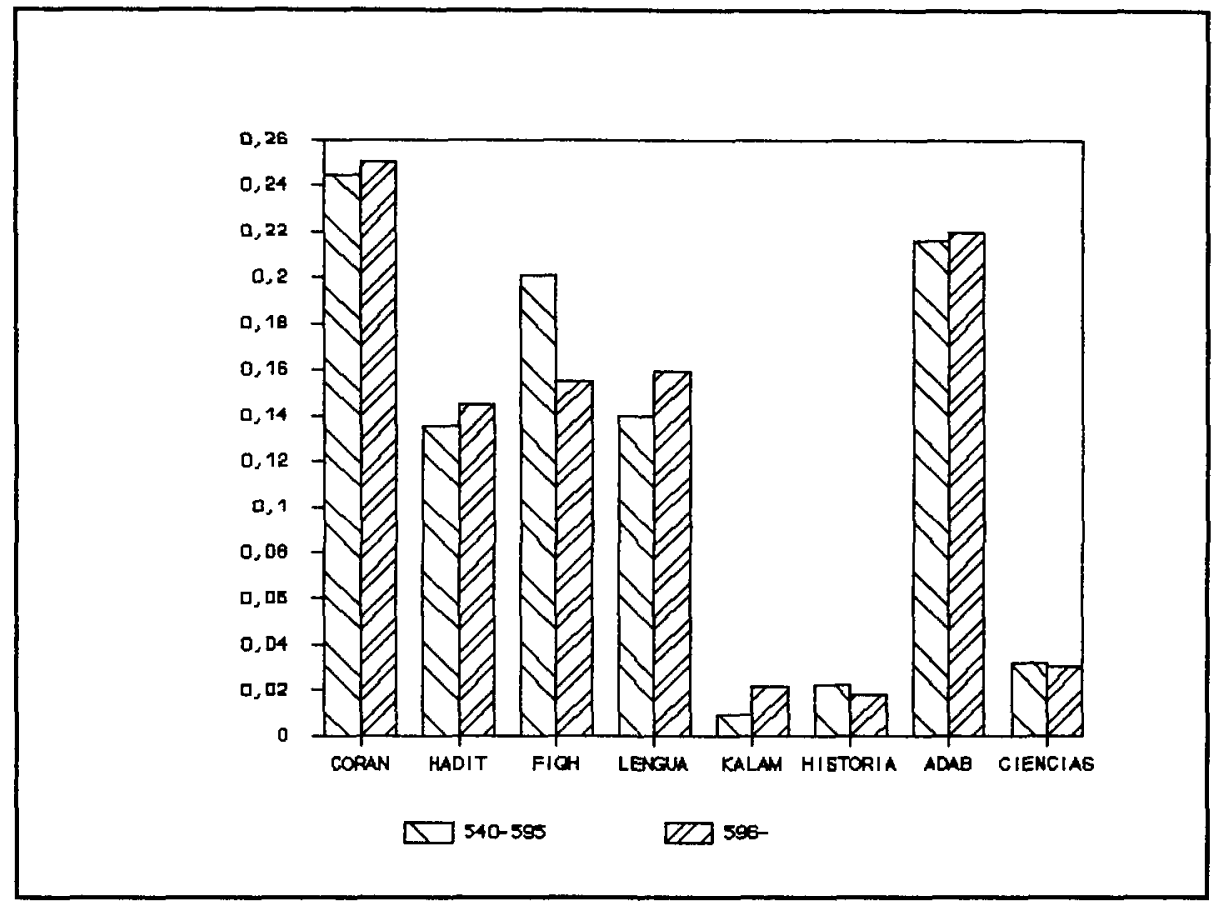

GRAFICO 1

En conclusión, la expresión samica min [fulān] parece tener dos sentidos en la Takmila. En primer lugar indica un modo de transmisión concreto: la audición; y, en segundo término, la encontramos asociada preferentemente al hadit.

Pasemos ahora a considerar otros aspectos de la audición en la Takmila.

Se distingue claramente sami ${ }^{c} a$ de otras expresiones relacionadas con la transmisión: samica Sahih al-Bujärt min [fulān] wa-ajada 'an-hu al-qirä'ät ("escuchó el Sahịh de al-Bujārī de [fulano] y tomó de él las lecturas coránicas") ${ }^{19}$; samic $\dot{a}$ al-Muwatta' min [fulān] wa-âyāza la-hu ("escuchó el Muwatta' de [fulano] y le dio licencia para transmitir") ${ }^{20}$; samic $a$ min [fulän] wa-tafaqqaha

(19) IA(Codera+Alarcón) $n^{2} 1874$. Expresiones similares son muy frecuentes. Otros ejemplos: IA(Cairo), $n^{\text {os }} 1534,1541,1665,2117$; LA(Codera) $n^{2} 1656$; IA(Codera+Alarcón) $n^{\text {os }}$ 1814, 2089.

(20) IA(Cairo) $\mathrm{n}^{2} 2184$. Otras referencias de las múltiples que se podrían citar: $\operatorname{IA}\left(\right.$ Cairo) $\mathrm{n}^{\text {o8 }} 1315,1515$, $1522,1523,1560,1632$; IA(Codera+Alarcón) $n^{\circledR} 2068$; IA(Alarcón) $n^{\circledR} 2239$. 
$b i-h i$ ("escuchó de [fulano] y estudió derecho con ell") $^{21}$. Estos ejemplos, a los que podrían affadirse muchos más, confirman que Ibn al-Abbār hace uso de un lenguaje técnico y preciso.

En las sesiones de audición, un discípulo podía hacer de lector en lugar del maestro. Tal discípulo tendría una relación muy estrecha con su maestro. Así samica min [fulān] wa-jtașsa bi-hi wa-huwa kāna al-qāri' 'alay-hi li-mā yusmic ("escucho de (fulano, el maestro), le fue especialmente asiduo e hizo de lector de cuanto (el maestro) hacía escuchar") ${ }^{22}$. No se puede saber hasta qué punto era frecuente que el maestro escogiera un lector entre sus discípulos, pues en ocasiones los maestros son los que dictan personalmente: laqiya [fulän] wa-samic a min lafzi$h i b a^{\mathrm{c}} d$ tawälïfi-hi ("encontró a [fulano] y escucho de su propia boca algunas de sus obras") ${ }^{23}$. No son infrecuentes los discípulos que permanecieron largos años junto a un maestro: samica bi-baladi-hi min [fulān] wa-lāzama-hu nahw cišìn sanat $^{\text {an }}$ ("escuchó en su ciudad de [fulano] y le fue asiduo durante unos veinte años") ${ }^{24}$. Tampoco es infrecuente encontrar rebatidas las opiniones del maestro: sämic a bi-baladi-hi [fulān] wa-näzara calay-hi fi uṣul al-fiqh ("escuchó en su ciudad de [fulano] y discutió con él sobre los fundamentos del derecho" ${ }^{25}$.

A las sesiones de audición podían acudir niños: samica fí șugari-hi min [fulān] Muwatta' Mālik wa-ba'd Garib al-hadīt li-' Ubayd Allāh ("escuchó en su infancia de [fulano] el Muwatta ${ }^{\mathrm{c}}$ de Māilik y parte del Garỉb al-hadīt de "Ubayd Allāh") ${ }^{26}$. En cuanto a la edad del maestro, existía en general una relación entre longevidad y prestigio ${ }^{27}$. Un ejemplo de longevidad es el siguiente: samic $a$

(21) IA(Cairo) 1550. Otras referencias: IA(Cairo) $n^{0 s} 1880,2018,2081$; IA(Codera+Alarcón) $n^{\text {os }} 2028$, 2078; LA(Alarcón) $n^{2} 2762$.

(22) IA(Cairo), $\mathrm{n}^{\mathrm{9}} 220$. Una serie de sesiones (veintiuna) multitudinarias y renombradas, que tuvieron lugar en ramadān del año 534 (abril-mayo 1140), estuvieron dedicadas al Sahih de al-Bujārī; leyó en aqueila ocasión $\mathrm{Ibn}$ "Ubayd Allāh, discípulo predilecto del transimisor Suraỵ b. Muhammad. Véase IA(Cairo), $n^{\text {os }} 2080,239,1493$; IA(Codera) $n^{2} 1633$. Otros ejemplos en IA(Ċairo) $n^{2} 698$.

(23) IA(Cairo) $\mathrm{n}^{2} 1299$.

(24) IA(Codera+Alarcón), $n^{\circledR} 1820$.

(25) IA(Codera+Alarcón), $\mathrm{n}^{\mathrm{Q}} 1911$.

(26) IA(Cairo) $n^{2} 2027$. Otras referencias: IA(Cairo) $n^{2} 497$. Los tratadistas han discutido mucho sobre la edad mínima que debe tener un discípulo para poder "escuchar" las tradiciones proféticas. Según unos no es recomendable antes de los veinte años o los treinta. Al-Nawāwī dice que en su época la opinión general es que se pueden escuchar hadít-es cuando se tiene la facultad de entenderlos exactamente y de escribirlos, y esa facultad se manifiesta en diferentes edades según los individuos. Según el qāạ̄ 'Tyād, el límite mínimo es de cinco años. Véase Taqrỉb, pp. 101-102.

(27) Así se muestra en J. Zanón, "Demografía y sociedad: la edad de fallecimiento de los ulemas andalusíes", Actas del Simposio "Saber religioso y poder político en el islam" (en prensa). 
min [fulān] ... wa-laqiya-hu bi-Turtūsa wa-qad qāraba al-mi'a fĩ sinni-hi ("escuchó de [fulano] y le encontró en Tortosa cuando contaba cerca de cien af́os de $\left.\operatorname{edad}^{\prime 2}\right)^{28}$.

La audición podía ser recíproca: samica min-hu Ibn Baskuwāl wa-samica min-hu huwa ayd $d^{\text {en }}$ fa-tadabbaŷā ("Ibn Baskuwāl escuchó de él, y también éste escuchó de Ibn Baskuwāl; eran simétricos en la transmisión") ${ }^{29}$.

La audición de una obra podía ser total o parcial: sami a min [fulān] al$A r b a^{\mathrm{c}} \overrightarrow{i n}$ hadit ${ }^{\mathrm{an}}$ min $\hat{y}$ mm $^{\mathrm{c}} i-h i$ wa-l-nisf al-awwal min al-Sïra li-bn Ishāq (escuchó de [fulano] la totalidad de al-Arba ${ }^{\mathrm{c}} \overline{\mathrm{n}}$ hadit ${ }^{\text {an }}$ y la primera mitad de la Sìra de Ibn Ishāq") $)^{30}$. En ocasiones se especifica que un discípulo escuchó poco (tiempo) o al contrario: $\operatorname{sami}^{\mathrm{c}} a$ min [fulān] yasīr ${ }^{\text {an }}$ wa-aȳāza la-hu ("escuchó de fulano poco y le dio licencia para transmitir") ${ }^{31}$; sami $a$ min [fulān] $k a t \underline{t}^{\text {an }}$ wajtalafa ilay-hi mudat ("escuchó de [fulano] mucho (tiempo) y le sucedió (en la dirección de las sesiones de audición) durante un período") ${ }^{32}$. En ocasiones, el maestro consideraría que el discípulo no tenía capacidad suficiente, y le negaba la licencia para transmitir: samica min [fulān] Kitāb al-Sìra li-bn Ishāq wa-lam yuŷiz ("escucho de [fulano] el Kitāb al-Sīra de Ibn Ishāq y no le dio licencia para transmitir") ${ }^{33}$.

Es sabido que hasta época nazarí no hubo madrasa-s, lugares específicos para la ensefianza ${ }^{34}$. La Takmila apenas informa de lugares concretos (sí de poblaciones) donde tenían lugar las sesiones de audicion. Estos solían ser las mezquitas, pero también casas particulares, tiendas ${ }^{35}$, etc. Por curioso, citamos un caso especial:

(28) IA(Cairo) $\mathbf{n}^{2} 735$.

(29) IA(Cairo) $n^{9} 398$. Al-Nawāwī dedica un capítulo al caso de la simetría o reciprocidad en la transmisión del hadit en su Taqrib, pp. 225-226. Manuela Marín ha consagrado recientemente un amplio estudio a- $\mathrm{Ibn}$ Baškuwāl. Véase Ibn Baškuwāl, Kitẩb al-mustagiținn bi-llāh, ed. crítica y estudio, Madrid, 1991.

(30) IA(Cairo) $n^{2} 1593$. Otros ejemplos: IA(Cairo) $n^{\text {os }} 239,1376,1858$ bis, 2167, IA(Codera+Alarcón) $\mathrm{n}^{\text {os }} 1810,1922,1969,2090$.

(31) IA(Cairo) $n^{2} 495$. Otras referencias: IA(Cairo) $n^{\text {os }} 276,1491$.

(32) IA(Cairo) $\mathrm{n}^{2} 221$. Otras referencias a discípulos que se mantuvieron largo tiempo al lado de sus maestros en IA(Cairo) $n^{03}$ 693, 1573; IA(Codera+Alarcón) $n^{\circledR} 2088$.

(33) IA(Cairo) $\mathrm{n}^{\circ} 1515$.

(34) La primera madrasa en al-Andalus es ya de época nazarí. Véase $M^{\mathrm{a}}$ Jesús Rubiera, "Datos sobre una «madrasa» en Málaga anterior a la nașī de Granada" Al-Andalus, XXXV (1970), pp. 223-6.

(35) En IA(Cairo) $n^{2} 1370$, un discípulo escucha de su maestro en su tienda (hānūt) de Bấb alZayyātìn de Almería. 
un personaje escucho de cuatro maestros en el camino de la aceifa contra Cutan$\mathrm{da}^{36}$.

\subsection{Expresión ajada [materia], [obra] 'an fulān}

Si tras la expresión samic a min [fulän] en un alto porcentaje no se dejaba explícito el objeto de la audición, tras la expresión ajada can [fulān] ocurre lo contrario. La proporción de referencias sin contenido es relativamente reducida:

\begin{tabular}{||l|r|r||}
\hline Sin contenido & 375 & $27,4 \%$ \\
\hline Materias & 913 & $66,7 \%$ \\
\hline Obras & 81 & $5,9 \%$ \\
\hline & & \\
\hline Total & 1369 & $100 \%$ \\
\hline
\end{tabular}

El siguiente cuadro muestra la distribución de las materias:

\begin{tabular}{||l|r|r||}
\hline Lecturas coránicas ${ }^{37}$ & 624 & $68,3 \%$ \\
\hline Hadīị & 3 & $0,3 \%$ \\
\hline Fiquh & 8 & $0,9 \%$ \\
\hline${ }^{\text {'Arabiyya/luga }}$ & 170 & $18,6 \%$ \\
\hline Adab & 92 & $10,1 \%$ \\
\hline Tỉbb & 10 & $1,1 \%$ \\
\hline Kalām & 6 & $0,7 \%$ \\
\hline & & \\
\hline Total & 913 & $100 \%$ \\
\hline
\end{tabular}

(36) IA(Cairo) $\mathrm{n}^{2}$ 1304. Sobre la aceifa de Cutanda véase $\mathrm{M}^{\mathrm{a}}$ Jesús Rubiera y Mikel de Epalza, Xàtiva musulmana (segles VIII-XIII), Xàtiva, 1987, p. 155.

(37) Las lecturas coránicas citadas explícitamente, como qirä'at Nāfíc ("la lectura de Nāfi ${ }^{\mathrm{c} "}$ ), qirä'at Ibn Katīir ("la lectura de Ibn Katīi"), etc, se han considerado "obras" para el recuento estadístico, mientras que las expresiones más generales, como al-qirā'āt ("las lecturas"), o, incluso alqirä'ät $a l-s a b^{c}$ ("las siete lecturas"), se han considerado materia. Se ha razonado que cada qirā'a concreta es al Corán lo que cada colección canónica de tradiciones es al hadit . 
Todas las disciplinas islámicas fundamentales aparecen representadas, pero destacan por su alta frecuencia las lecturas coránicas (qirä́ät), la filología ('arabiyyalluga) y el adab, que juntas suman un $96 \%$. Parece claro, pues, que la expresión ajada can es una fórmula aplicada fundamentalmente a las ciencias coránicas y filológicas, en tanto que samica min lo es para las ciencias de la tradición. Pero ¿puede suponerse que la formula ajada ${ }^{\mathrm{c}}$ an implica sima $\bar{a}^{\mathrm{c}}$ como modo de transmisión? Cabría pensar afirmativamente, puesto que, en caso contrario, no se explicaría que las ciencias coránicas y la filología nunca aparezcan tras la fórmula sami $a$ min. Sin embargo se encuentran referencias que indican que la expresión ajada ${ }^{\mathrm{c}}$ an no expresa en sí un modo de transmisión concreto, como: ajada ${ }^{\mathrm{c}} a$ n [fulān] jutaba-hu munāwalat" ("tomó de [fulano] sus sermones del viemes por

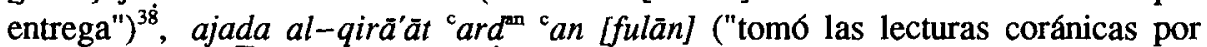
presentación de [fulano]") ${ }^{39}$, ajada musannaf al-Nisä't qirä'at ${ }^{\text {an }}$ 'an [fulän] ("tomó los Sunan de al-Nisāì por recitación de [fulano]") ${ }^{40}$, y también: ajada ${ }^{~} a n$ [fulān] Maqāmāt al-Harīì bayna qirā'a wa-simāa a ("tomó de [fulano] las Maqamas de al-Harīiri ya por recitación ya por audición") $)^{41}$.

En vista de todo lo anterior optamos por considerar que la formula ajada ${ }^{\mathrm{c}} a n$ se aplica fundamentalmente a las ciencias coránicas y a las filologicas, pero no implica un modo concreto de transmisión. En los casos en que no se indique otra cosa, este sería la audición, el modo más habitual.

Veamos a continuación cómo se distribuyen las obras citadas:

\begin{tabular}{||l|r|r|}
\hline Obras sobre lecturas coránicas & 34 & $42 \%$ \\
\hline Obras y colecciones de hadì & 22 & $27,2 \%$ \\
\hline Obras de derecho & 8 & $9,9 \%$ \\
\hline Obras de gramática & 6 & $7,4 \%$ \\
\hline Obras de adab y poesía & 8 & $9,9 \%$ \\
\hline Obras históricas/biográficas & 3 & $3,7 \%$ \\
\hline & & \\
\hline Total & 81 & $100 \%$ \\
\hline
\end{tabular}

(38) IA(Cairo) $n^{2} 1514$.

(39) IA(Codera+Alarcón) $n^{0 s}$ 1855, 1970.

(40) LA(Cairo) $n^{2} 1712$.

(41) IA(Cairo) $n^{2} 1581$. 
En el cuadro precedente se observa algo parecido a lo ocurrido en el caso de la expresión samic a min. Allí, cuando Ibn al-Abbār no indicaba la obra concreta que se transmitía, sino la materia, la expresión se aplicaba al hadit. Sin embargo, cuando señalaba obras, éstas podían pertenecer a cualquier ciencia islámica, pero, preferentemente, al hadït. Aquí, la expresión ajada ${ }^{\mathrm{c}}$ an se aplica sobre todo a las ciencias coránicas y filológicas cuando se trata de materias. Cuando se citan obras concretas, éstas pertenecen a cualquier disciplina islámica, aunque, preferentemente, a las qirā'ät.

A proposito de la expresión samic a min hemos visto una serie de peculiaridades relativas a la audición señaladas en la Takmila. Tras la fórmula ajada ${ }^{\mathrm{c}}$ an también se encuentran datos concretos sobre la transmision, pero en mucha menos cantidad. La referencia más destacable es la siguiente: laqiya [fulān] șabiyy ${ }^{\text {an }}$ wa-ajada ${ }^{\text {c } a n-~}$ hu fĩ tilka $l-h a ̈ l$ fa-li-dälika lam yuhaddit 'an-hu ("encontró a fulano y tomó (lecciones) siendo un nifo, por eso no transmitio de ell") ${ }^{42}$.

\subsection{Expresión qara'a calà [fulān] (obra)}

Son muy escasas las referencias en las que se halla la fórmula qara'a 'alà [fulān] (obra): 90 en total. Debe identificarse con el modo de transmisión por recitación o lectura. Su escasa frecuencia puede deberse al hecho de que en las sesiones de audición se escogería a un solo individuo, un discípulo aventajado o predilecto, para realizar la función de qãri' o lector. Éste recibiría la transmisión por recitación, y el resto de los discípulos, por audición. Por otro lado se observa que, frente a las formulas samica min y ajada ${ }^{c} a n$, tras las que apenas se citan obras, con la expresión qara'a ${ }^{c}$ alà sucede lo contrario: Ibn al-Abbār suele señalar la obra concreta que lee o recita un qāri'.

\begin{tabular}{||r|r|r|}
\hline Materias $^{43}$ & 6 & $6,7 \%$ \\
\hline Obras & 75 & $83,3 \%$ \\
\hline Sin contenido & 9 & $10 \%$ \\
\hline & & \\
\hline Total & 90 & $100 \%$ \\
\hline
\end{tabular}

(42) IA(Cairo) $\mathrm{n}^{2} 1309$.

(43) En concreto, adab (5) y ${ }^{c}$ arabiyya (1). 
En algunas ocasiones no es el biografiado quien recita sino el que escucha la recitación de un condiscípulo de mayor prestigio: samica min [fulän] Sahih alBujāri bi-qirä'at Ibn 'Ubayd Allāh ("escuchó de [fulano] el Șahih de al-Bijāāi en la lectura de Ibn "Ubayd Allāh") ${ }^{44}$. Hemos visto en el apartado 2.2. que el fundador de la escuela mālikí, Mālik b. Anas, consideraba de igual valor la audición y la recitación. Pero, según acabamos de seffalar, el qāri' o lector/recitador tiene un papel sobresaliente frente al mero auditor: 1) Ibn al-Abbār suele señalar la obra concreta que se lee o recita; en cambio, raramente indica la obra transmitida por audición, y 2) a veces nos ofrece el nombre del qãri' cuando no se trata ni del maestro ni del discípulo biografiado.

A continuación se ofrece el recuento de referencias por obras, agrupadas según las materias:

\begin{tabular}{||r|r|r|}
\hline Corán & 30 & $40 \%$ \\
\hline Obras de ciencias coránicas & 1 & $1,3 \%$ \\
\hline Obras de hadīt & 18 & $24,0 \%$ \\
\hline Obras de fiq̣h & 14 & $18,7 \%$ \\
\hline Obras de filología & 3 & $4 \%$ \\
\hline Obras de adab & 5 & $6,7 \%$ \\
\hline Obras de historia/biografías & 4 & $5,3 \%$ \\
\hline & & \\
\hline Total & 75 & 100 \\
\hline
\end{tabular}

Todas las disciplinas islámicas están representadas, pero el Corán se destaca sensiblemente. Evidentemente el libro sagrado se recitaba según alguna de las lecturas canónicas. Así: qara'a al-Qur'ān 'alà [fulän] bi-l-sab ("recitó el Corán ante [fulano] según la siete lecturas canónicas" $)^{45}$. No puede pensarse que la expresión qara'a $a^{\circ}$ alà tenga alguna relación especial con las lecturas coránicas, como hemos visto que sucede en parte con la expresión ajada ${ }^{c} a n$. El mayor porcentaje de citas al Corán debe verse, más bien, como índice del gran desarrollo de las ciencias

(44) IA(Cairo) $n^{\text {os } 239,637,1493 ; ~ I A(C o d e r a) ~} n^{2} 1633$. Sobre Ibn 'Ubayd Allāh véase IA(Cairo) $n^{9}$ 2080.

(45) LA(Cairo) $\mathrm{n}^{2}$ 1459; LA(Codera+Alarcón) nº 1891. 
coránicas en al-Andalus, como puede observarse en el gráfico 1, ya presentado ${ }^{46}$. Por otro lado hay que considerar que: 1) el Corán debe ser conocido por todo buen musulmán; 2) el Corán es necesario para los estudios de usül al-fiqh o fundamentos del derecho; 3) las ciencias coránicas y las filológicas guardan una estrecha relación.

\subsection{Expresión ẫāza la-hu}

Se ha señalado más arriba que los modos de licencia (iŷāza) pueden ser muy variados, y así se refleja en la Takmila. Se ha contabilizado un total de 1301 casos en los que aparece la expresión aŷāza la-hu ("le dio licencia para transmitir"), o alguna otra equivalente. Solamente en contadas ocasiones se deja explícito el contenido de la $i \hat{y} \bar{a} z a$, que suele ser poco concreto, según se puede observar en la siguiente relación:

\begin{tabular}{|c|c|}
\hline 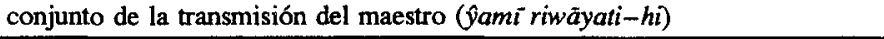 & 8 \\
\hline lo que el maestro había transmitido ( $m \bar{a}$ rawā-hu) & 12 \\
\hline $\begin{array}{l}\text { lo que el maestro había transmitido y compuesto ( } m \bar{a} \text { rawā-hu wa-allafa- } \\
h u / \text { sannafa-hu}\end{array}$ & 18 \\
\hline obras concretas & 8 \\
\hline
\end{tabular}

Sobre las modalidades de îyāza reflejadas por la Takmila, caben citar las siguientes referencias. No era necesario que el receptor de la licencia hubiera llegado a conocer personalmente al maestro: aýāza la-hu wa-lam yalqa-hu ("le dio licencia para transmitir sin encontrarse con él") ${ }^{47}$. O, si acaso le hubiera conocido personalmente, no era necesario que el discípulo le escuchara: aŷāza la-hu wa-lam yasma $a^{c}-h u$ ("le dio la licencia sin haberle escuchado") ${ }^{48}$. Como la iŷãza no implica

(46) No se puede pensar que Ibn al-Abbār dé un trato de preferencia a los lectores coránicos. L. Pouzet señala al comienzo de su estudio sobre los lectores coránicos andalusíes en Oriente que, en los últimos siglos de la presencia musulmana en al-Andalus, el Occidente musulmán se convirtió en "leader incontesté" en esta materia ("Un type d'échange culturel", Actas del XII Congreso de la U.E.A.I. (Málaga, 1984), Madrid, 1986, p. 658). Por mi parte, he analizado el diccionario biográfico oriental de muqri'-s, Ma ${ }^{c}$ rifat al-qurrā' de al-Dahabî (m. 748/1348 o 753/1352), donde cabe encontrar las biografías de los lectores coránicos más destacados del mundo islámico a los ojos de un ulema oriental. Un recuento de los lectores coránicos biografiados en esta obra sugiere que, en la segunda mitad de la época almorávide, y sobre todo, en época almohade, es cuando esta actividad en al-Andalus goza de un gran aprecio en todo el mundo islámico, hasta el punto de que en el intervalo de los lectores fallecidos entre 551/1156-600/1203 (personajes que pudieron formarse en la segunda mitad de la época almorávide o primera de la almohade) la representación andalusí es superior a la del resto del mundo islâmico. (Datos tomados de mi Tesis Doctoral inédita).

(47) IA(Cairo) n 1664; IA(Codera+Alarcón) $n^{\circ} 1911$.

(48) IA(Cairo) $n^{2} 1381$. 
una relación directa, İon al-Abbār debe indicar del mismo modo la ausencia de relación, como constatar que efectivamente hubo un trato directo: aŷaza la-hu walaqiya-hu ("le dio la licencia habiéndose encontrado") ${ }^{49}$; aŷäza la-hu wa-samic $a$ $m i n-h u$ ("le dio la licencia habiéndole escuchado") ${ }^{50}$. Hemos visto más arriba, en una referencia sobre la audición, que la transmisión del saber podía ser recíproca. El modo concreto de transmisión sería indiferente. Ibn al-Abbār señala un caso de audición e $i \hat{y} a \bar{z} a$ recíprocas en las que él mismo está implicado: samictu min [fulān] wa-samica min-nì wa-aŷāza li bi-lafzi-hi wa-aŷaztu la-hu ("escuché de [fulano] y él escuchó de mí; me dio la îyáza personalmente y yo se la di a él" ${ }^{51}$. La transmisión de una obra podía efectuarse en parte por audición y en parte por $i \hat{y} \bar{a} z a^{52}$. El receptor de la $i \hat{y} a \bar{z} a$ podía ser un niño: âyāza la-hu yaddu-hu fí sigari-hi ("su abuelo le dio la licencia en su niñez") ${ }^{53} ; a \hat{y} a \overline{z a}$ la-hu [fulān] wahuwa ibn sitt sinin ("[fulano] le dio la licencia cuando contaba con seis años de edad") ${ }^{54}$. El aspecto que quizá llama más la atención son las licencias múltiples y las licencias generales, señaladas con bastante frecuencia. Por ejemplo: aŷazza la$h u$ [fulän] wa-li-bani-hi ("[fulano] le dio licencia a él y a sus hijos") ${ }^{55}$; dos

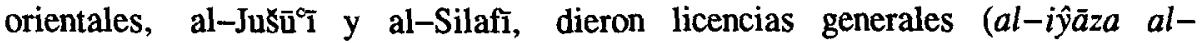
${ }^{\complement} \bar{a} m m a$ ) a los andalusíes ${ }^{56}$. Cuando Ibn al-Abbār señala una de estas iŷãzas generales, en cierta manera está indicando un posible eslabón débil en una cadena de transmisión: hadda ta 'an [fulän] bi-l-iŷāza al-"ämma ("transmitió de [fulano] con licencia general" $)^{57}$. Tal vez por esta razón sería raro que un maestro indicara explícitamente que transmitía a través de una $i \hat{y} a \bar{z} a$ general: $k \bar{a} n a$ yuhaddit $b i-l-$ iŷāza al- ${ }^{c} a \overline{m m a}$ wa-yaqūl bi-hã ("transmitía por licencia general y la declara$\left.\mathrm{ba}^{58}\right)^{58}$. La îyāza podía tambien denegarse $\mathrm{e}^{59}$. No son infrecuentes las peticiones de licencia efectuadas por el mismo interesado o por una tercera persona: istaŷazza

(49) IA(Codera+Alarcón) ne 1911.

(50) IA(Cairo) $\mathrm{n}^{\text {os }} 1301$ y 1738.

(51) IA(Cairo) $\mathbf{n}^{2} 1682$

(52) Por ejemplo: IA(Cairo) $n^{9} 1887$; LA(Codera+Alarcón) $n^{9} 1894$.

(53) IA(Cairo) $\mathrm{n}^{\circ} 826$.

(54) IA(Codera), $\mathrm{n}^{2} 1670$.

(55) IA(Codera) $\mathbf{n}^{2} 1642$.

(56) Las referencias son numerosas; baste con IA(Cairo) $n^{2} 442$.

(57) IA(Codera+Alarcón) $n^{2} 1832$.

(58) IA(Cairo) $n^{9} 1673$.

(59) IA(Cairo) $n^{\text {os }} 239,2099$; IA(Codera) $n^{2} 1613$. 
huwa li-nafsi-hi ("le pidio la licencia para sí mismo") ${ }^{60}$; istaŷāza la-hu [fulān] ([fulano] le pidio [al maestro] la licencia para [un tercero]") ${ }^{61}$.

\subsection{Expresión kataba}

Se ha contabilizado un total de 287 expresiones en las que aparece el verbo kataba "escribi6". Pero hay que distingir los casos seguidos de la preposición ilà (225), es decir, un $78,4 \%$, de los seguidos por otras preposiciones (62), que corresponde a un $21,6 \%$.

Con kataba ilà [fulān] se señala la transmisión por escrito. Es significativo que, de la mayor parte de los maestros que transmiten según esta modalidad, se señale su lugar de origen, y que la mayoría sean orientales. Se trataría, pues, de una transmision "por correspondencia", efectuada en casos particulares. El discípulo no podría ponerse en contacto directo con un maestro, ante la imposibilidad de realizar un viaje, y solicitaría la transmisión de determinado saber por escrito a través de terceros. Por otro lado, no se expresa en ningún caso el contenido de lo que se transmite. Solamente en dos ocasiones se especifica la licencia para transmitir, pero no el contenido concreto: kataba ilay-hi bi-iỹazza mā rawà-hu ("le escribió con licencia de transmitir lo que había transmitido") ${ }^{62}$. En la segunda referencia está implicado el mismo Ibn al-Abbār y cierto maestro oriental: kataba ilay-hi yuŷtz la-hu wa-li ŷami riwāyati-hi ... wa-anā ibn "āmayn ("escribió [a fulano] dándole licencia a él y a mí de transmitir todo lo que él había transmitido...; yo tenía entonces dos años") ${ }^{63}$.

En las expresiones kataba seguidas de las preposiciones 'an [fulān] o li[fulān] o sin preposicion, el sujeto no es el maestro-transmisor sino el discípulo (el biografiado). Se señala entonces el mero acto de escribir o de copiar. No se trata, pues, de un modo de transmisión. Así podía ocurrir en las sesiones de audición: kataba mā samic a ("escribio lo que escuch6") ${ }^{64}$; samic a min [fulän] Sahīh alBujāri wa-kataba-hu bi-jatți-hi ("escuchó de fulano el Sahihih de al-Bujārī y lo escribí de su puño y letra" $)^{65}$. Kataba bayna yaday-[fulän] o li-[fulän] suele estar referido a la función de secretario de un magistrado. Así: șahiba al-qādi

(60) IA(Cairo) $\mathrm{n}^{\mathrm{Q}} 1514$.

(61) IA(Cairo) $\mathrm{n}^{\text {os }} 1514,1678$.

(62) IA(Cairo) $n^{9} 570$.

(63) IA(Cairo) $n^{2} 2105$

(64) IA(Cairo) $n^{2} 2057$

(65) IA(Cairo) $n^{9} 878$. 
[fulān] wa-lāzama-hu wa-kataba bayna yaday-hi ("acompaño al cadí [fulano],

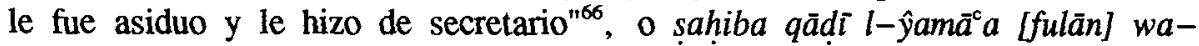
jtassa bi-hi wa-kataba la-hu ("acompañó al cadí de la comunidad [fulano], tuvo con él una relación particular y le hizo de secretario") ${ }^{67}$.

\subsection{Expresión nāwala o equivalentes.}

En las biografías examinadas de la Takmila, las expresiones nāwala, munäwala o tanāwala, que denotan la transmisión por presentación, aparecen en catorce ocasiones. Es, por tanto, un tipo de transmisión muy poco frecuente. Solamente en dos casos no se cita la obra o la materia transmitida. Las obras citadas pertenecen a géneros variados; los comentarios al Corán, las colecciones de tradiciones y el Muwatta' aparecen en más de una ocasión. Son curiosos dos casos de transmisión del conjunto de los libros de sendas bibliotecas ${ }^{68}$. Como no parece probable que el discípulo los copiara, se trataría de regalos de bibliotecas con autorización para transmitir el contenido de sus libros.

\subsection{Expresión tafaqqaha bi-[fulān].}

("Estudió derecho con [fulano"). Aparece en 84 ocasiones. En ningún caso se señala obra o rama concreta del derecho. Expresa la materia objeto de enseñanza (fiqh), y no implica un modo concreto de transmisión. Éstos habrán de señalarse mediante las formulas consabidas, como, por ejemplo: tafaqqaha bi-[fulän] waqara'a 'alay-hi al-Mudawwana ("estudió derecho con [fulano] y recitó ante él la Mudawwana") ${ }^{69}$. Podría considerarse sinónima la expresión darasa 'alà [fulān] ("estudió con"), contabilizada en veinte ocasiones. Pero se diferencia, al menos formalmente, en que casi siempre es explícita la materia: darasa 'alà [fulān] al$f i q h^{70}$ (recordemos que el fiqh está implícito en el verbo tafaqqaha). La sinonimia queda clara en la siguiente cita: tafaqqaqa bi-[fulān] wa-darasa fi maŷlisi-hi $i^{71}$. A propósito de esta expresión, puede resultar de interés la mención de un jurista, fallecido en Murcia en 574/1178, que tuvo determinados cargos en la administración judicial de Murcia, Játiva y Orihuela. Ibn al-Abbār señala que "enseñó el fiqh

(66) IA(Cairo) $\mathrm{n}^{\circ} 189$.

(67) IA(Cairo) $\mathrm{n}^{9} 1724$.

(68) IA(c) 1626 y IA 1560.

(69) IA(Cairo) $\mathrm{n}^{\text {os }} 1541$ y 1569.

(70) En un sólo caso darasa no se refiere al derecho, sino al Kitāb de Sỉbawayhi: IA(Cairo) $\mathrm{n}^{8} 1469$.

(71) IA(Cairo) $n^{2} 2050$. 
según la escuela cordobesa" (darrasa al-fiqh calà l-tariqqa al-qurțbiyya) ${ }^{72}$. Esta "escuela cordobesa" debe identificarse con la casuística ( $f u r \bar{u}^{\mathrm{c}}$ al-fiqh) desarrollada en época omeya. La referencia no carece de importancia, ya que pone de manifiesto el mantenimiento de la casuística tradicional en Šarq al-Andalus frente a la tendencia, en época almorávide y almohade, a dar un mayor énfasis a las fuentes del derecho ( $u s \bar{u} l$ al-fiqh). Dentro de este último movimiento se suele destacar a otro sarqī, Abū Bakr al-Ṭurțīsīi (m. 520/1126) y a Abū Bakr Ibn al-c'Arabī (m. 534/1149) ${ }^{73}$.

\subsection{Expresión haddata ${ }^{c}$ an [fulān].}

Aparece en 85 ocasiones. Se expresa la obra transmitida en la mitad aproximada de las referencias. Dichas obras son de todo tipo: ciencias coránicas, tradiciones, derecho, filología y bellas letras. En un segundo grupo de referencias no se deja explícita la obra transmitida, pero se hace constar que la transmisión se efectuó con $i \hat{y} a ̈ z a$ o licencia (14 ocasiones). En el resto de referencias no consta más que el nombre del transmisor. Esta expresión no parece implicar un modo de transmisión concreto. Tampoco indica una materia específica. Es probable que Ibn al-Abbār la utilice como expresión sinónima de rawà "an ("transmitió de"). La diferencia puede estar en que con esta última fórmula señala la transmisión del maestro al personaje biografiado, mientras que con haddata ${ }^{\circ}$ an indica la transmisión del personaje biografiado a su(s) discípulo(s) ${ }^{74}$.

\subsection{Expresión rawà can [fulān].}

Aparece en un 989 ocasiones. Rawà can ("transmitió de"), y como sinónimo, la-hu riwāya can ("tiene transmisión de"), se aplica a la transmisión en sí: se trata de la constatación de la transmisión. Quizá por esta razón es raro que tras la expresión rawà ${ }^{c}$ an se declare la obra o materia concretas transmitidas ${ }^{75}$. En cambio, sí es muy frecuente que a continuación se señale el objeto de la transmisión tras otras fórmulas, como samic a min, ajada can etc. Por ejemplo: rawà can [fulān] samica min-hu Muwatta' Mālik ("transmitió de [fulano]; escuchó de él el Muwatta'

(72) IA(Cairo) $\mathrm{n}^{2} 189$

(73) Cfr. mi Tesis Doctoral inédita, p. 180.

(74) Ibn al-Abbār utiliza muy corrientemente la expresión hadda a ${ }^{c}$ an-hu [fulān] cuando se refiere a los discípulos del biografiado. Pero, como se ha justificado más arriba, la parte de las biografias relativa a los discípulos de los personajes biografiados no se ha tomado en cuenta para la realización del presente trabajo.

(75) Las excepciones quedan prácticamente reducidas a las siguientes: IA(Cairo) $\mathrm{n}^{\text {os }} 148,215,434,451$, 735, 1841, 1295, 1297 y 1354; IA(Codera+Alarcón) n ${ }^{\text {os }} 1610,1914,1992,20212086$ y 2094; IA(Alarcón) $\mathrm{n}^{\mathrm{9}} 2361$ bis. 
de Mālik") ${ }^{76}$. En algún caso se expresa el carácter o la calidad de la riwāya. Así: lam yadbit mã rawà can [fulān] ("no fijo con precisión lo que había transmitido de [fulano]") $)^{i \eta}$. Las riwäya-s "altas", es decir, transmisiones con $i s n a \bar{d} d-\mathrm{es}$ o cadenas de transmisión breves, eran muy apreciadas por encontrarse más cerca de las fuentes ${ }^{78}$ : ' $a l d$ [fulān] $i^{\mathrm{C}}$ tamada $l i-{ }^{c} a l w$ riwāyati-hi ("se apoyb en [fulano] por lo alto de su riwāya ${ }^{79}$. De ordinario se produce una transmisión "alta" cuando un personaje recibe alguna enseñanza en edad temprana y la transmite en edad avanzada. De aquí que muchos maestros buscaban discípulos muy jovenes ${ }^{80}$. Una cadena de transmisión integrada por abuelo-padre-hijo podría fácilmente implicar un isnād "alto". En este sentido podría interpretarse que Ibn al-Abbăr se ve obligado a declarar: la-hu riwāya 'an abi-hi ${ }^{\circ}$ an ŷaddi-hi wa-lam ya $\mathrm{c} l u$ isnādu-hu ("tiene transmisión de su padre, tomándola de su abuelo y su isnād no es alto") ${ }^{81}$. En escasas ocasiones se hace referencia a alguna riwäya de prestigio, como la del Muwatta' de Yahyà b. Yahyà (m. 234/848) ${ }^{82}$. Finalmente, señalaremos que frente a la riwäya o mera recepción, memorización, fijación por escrito y transmisión de las ciencias islámicas, que ocupa la parte más importante de la actividad intelectual, existe un estudio crítico (dirāya), que, aunque minoritario, gozaba de gran estima entre los autores árabes ${ }^{83}$. Así: kānat al-dirāya aglab 'alay-hi min al-riwāya ("se interesó mucho más por el conocimiento crítico que por la transmisión") $)^{84}$.

\section{Conclusiones.}

\subsection{Sobre la terminología empleada.}

Las formulas o expresiones empleadas más usualmente por Ibn al-Abbār en su Takmila para indicar la recepción de la transmisión de los personajes biografiados

(76) IA(Cairo) $\mathrm{n}^{2}$ 1410. Los ejemplos se pueden multiplicar.

(77) IA(Cairo) $n^{2} 1632$. Sobre la exactitud y fijación de los hadît -es (dabt) véase Taqrib, pp. 80 y ss.

(78) Taqrib, pp. 193-199.

(79) IA(Cairo) $\mathrm{n}^{\mathrm{9}} 1381$.

(80) Taqrib, p. 198 y n. 4.

(81) IA(Cairo) $\mathbf{n}^{2} 1606$

(82) IA(Cairo) $n^{\text {os }} 298,1520$ y 2122; LA(Codera+Alarcón) $n^{2} 1720$. Sobre esta transmisión concreta, conocida tanto en Oriente como en Occidente, véase M. A. Makki, Ensayo sobre las aportaciones orientales en la España musulmana, Madrid, 1968, p. 100.

(83) La oposición riwãya-dirāya se encuentra en todas las ciencias islámicas. Véase el prefacio de W. Marçais al Tagrib de al-Nawāwī, pp. i-iv.

IA(Cairo) $n^{2} 1497$. 
pueden estar señalando bien la forma, bien el contenido de la transmisión o ambos tipos de información al mismo tiempo. Las fórmulas qara'a 'alà, aŷāza li-, nāwala y kataba ilà expresan claramente la recepción de la transmisión por recitacion, licencia, entrega y escrito respectivamente. Otras expresiones implican materias o disciplinas concretas, pero no un modo de transmisión. Así, tafaqqaha, y según parece, darasa, están asociadas al derecho. Las fórmulas $\operatorname{sami}^{\mathrm{i} a}$ min y ajada 'an parecen señalar tanto los modos de transmisión como determinadas materias con preferencia. En el primer caso, tradiciones proféticas por audicion; en el segundo, ciencias coránicas y filologicas por audición o por algún otro modo de transmisión si así se indica. Finalmente, rawà ${ }^{\mathrm{c}}$ an y hadda $t{ }^{\mathrm{c}}{ }^{\mathrm{c}}$ an no hacen referencia ni al modo ni al contenido, sino a la transmisión en sí misma.

\subsection{Sobre los modos de transmision.}

Según al-Nawāwī, los modos de transmisión del hadīt por orden descendente de valor eran: 1) $\operatorname{sam}^{c}{ }^{c}$ (audición), 2) qirä́a (recitación), 3) iŷa $\bar{z} a$ (licencia), 4) munāwala (entrega), 5) kitäba (escrito), 6) icläm (declaración), 7) wașiyya (testamento) y 8) wiŷâda (hallazgo).

Considerando en conjunto todas las ciencias islámicas, los modos de transmisión en al-Andalus durante las épocas almorávide y almohade según, no su valor intrínseco sino la frecuencia de su aplicación, seguirían el siguiente orden: 1) audición, 2) licencia, 3) escrito, 4) recitación y 5) entrega. Los dos primeros son los más frecuentes con gran diferencia. Por otro lado, no es fácil deducir de los datos aportados por la Takmila cuál era el rango o valor dado a cada una de tales formas de transmisión. Mālik $b$. Anas consideraba equivalentes la audición y la recitación, pero, como se ha apuntado en líneas anteriores, parece que el modo más apreciado era la recitación. El valor de la $i \hat{y} \bar{a} z a$ dependería de cada caso particular: no sería lo mismo la transmisión efectuada a través de una iyyaaza general que según una î̀āza particular o una îyāza acompañada de otra forma de transmisión. Los modos más controvertidos entre los teóricos en relación a su validez, a saber, íläm (declaración), wașiyya (testamento) y wiŷāda (hallazgo), no debían producirse, o apenas se daban en la práctica en al-Andalus durante el período citado, puesto que no se hallan citados en la Takmila en ninguna ocasión.

La Takmila nos ofrece algunos detalles y circunstancias particulares referentes a las formas de transmisión, según se ha señalado a lo largo del apartado 2. de este trabajo. La información resulta escasa si la comparamos con la proporcionada por el Taqrib de al-Nawāwī. Sin embargo tiene el interés de estar basada en la práctica, durante un período y en un lugar concretos. 